\title{
MINERALOGIA E FÍSICO-QUÍMICA DOS SOLOS DE MANGUE DO RIO IRIRI NO CANAL DE BERTIOGA (SANTOS, SP) ${ }^{(1)}$
}

\author{
R. M. PRADA-GAME RO ${ }^{(2)}$, P. VIDAL-TORRADO(3) $\&$ T. O. FERREIRA ${ }^{(4)}$
}

\begin{abstract}
RESUMO
A influência de condições halomórficas, hidromórficas e sulfato redutoras na mineralogia da fração argila e na geoquímica de três solos de mangue foi estudada no manguezal do rio I riri. A partir de uma transeção, foram escolhidos três perfis representativos dos solos de mangue da área nos quais foram descritas as condições geoquímicas e sua conseqüência sobre a mineralogia de seus respectivos solos. A análise mineralógica (DRX e EDS) e as condições físicoquímicas encontradas revelam a ocorrência de processos de piritização na área de estudo. A assembléia mineralógica está composta tanto por argilominerais alóctones (caulinitas, micas e esmectitas) como por argilominerais autóctones (micas, esmectitas e pirita). A partir de evidências provenientes da DRX e EDS, especula-se a formação de glauconita nestes solos. As condições de halomorfia e hidromorfia determinam valores de $\mathrm{E} h$ e $\mathrm{pH}$ sob os quais elementos como $\mathrm{Fe}^{2+} e$ SO encontram-se livres na solução do solo com tendência à estabilidade da pirita $\left(\mathrm{FeS}_{2}\right)$, favorecendo, portanto, o processo da piritização.
\end{abstract}

Termos de indexação: estabilidade de minerais, solos tiomórficos, pirita, glauconita.

(1) Parte de Tese de Mestrado da primeira autora, apresentada à Escola Superior de Agricultura Luiz de Queiroz - ESALQ/USP, Piracicaba (SP). Recebido para publicação em dezembro de 2001 e aprovado em novembro de 2003.

(2) Engenheira-Agrônoma MS em Sol os e Nutrição de Plantas pelo Departamento de Sol os e Nutrição de Plantas, E scola Superior de Agricultura Luiz de Queiroz - ESALQ/USP. Av. Pádua Dias 11, CEP 13418-900 Piracicaba (SP). E-mail: rprada@ycos.com

(3) Professor Associado do Departamento de Sol os e Nutrição de Plantas, ESALQ/USP. Bolsista do CNPq. E-mail: pablo@esalq.usp.br

(4) Doutorando do Departamento de Solos e Nutrição de Plantas, ESALQ/USP. Bolsista da FAPESP. E-mail: tiagoof@esalq.usp.br 


\title{
SUMMARY: MINERALOGY AND PHYSICAL CHEMISTRY OF MANGROVE SOILS FROM IRIRI RIVER AT THE BERTIOGA CHANNEL (SANTOS, SÃO PAULO STATE, BRAZIL)
}

\begin{abstract}
The present study evaluated the influence of hal omorphic, hydromorphic, and sulfate reduction conditions on sand fraction mineralogy and on thegeochemistry of threemangrove soils from thel riri River estuary. Three representative soil profiles sel ected from a transect had their geochemical conditions characterized and their effects on the mineralogy of the soils were described. The mi neralogical analyses (XRD and EDS) and the physicochemical (Eh and $\mathrm{pH}$ ) conditions found indicate the occurrence of pyritization in the investigated area. The mineralogical soil assembly is composed of both allochthonous (kaolinite, mica, and smectite) and autochthonous clays (mica, smectite, and pyrite). Based on theXRD and EDS data, it is speculated the possibility of glauconite formation in these soils. The hal omorphic and hydromorphic conditions determine the $\mathrm{Eh}$ and $\mathrm{pH}$ values. Under such environment $\mathrm{Fe}^{2+}$ and $\mathrm{SO}$ are found free the soil solution with a tendency to stabilize as pyrite $\left(\mathrm{FeS}_{2}\right)$, thus favorinf the pyritization process.
\end{abstract}

Index terms: mineral ogy stability, sulfidic soils, pyrite, glauconite

\section{INTRODUÇÃO}

Em regiões costeiras protegidas e de transição entre o mar e o continente (estuários, lagunas e planícies de maré), é comum o desenvolvimento de espécies vegetais hal ófitas adaptadas a condições de intensa salinidade e dehidromorfismo, denominadas mangue (Schaeffer-N ovelli, 1991; Suguio, 1992).

Os solos de mangue, tidos anteriormente como "solos indiscriminados de mangue" (Lepsch et al., 1983), são sol os hal omórficos desenvol vidos a partir de sedimentos marinhos e fluviais com presença de matéria orgânica e que ocorrem em regiões de topografia plana na faixa costeira sob a influência constante do mar. Todas as classes de sol os dessas áreas estão associadas à influência marcante da água, podendo ocorrer: Areias Quartzosas Marinhas ePodzóis hidromórficos (em terraços arenosos), sol os Gley, Orgânicos com tiomorfismo e solos Aluviais, principalmente da era Cenozóica (EMBRAPA, 1978; Lani, 1998).

Por estarem em ambientes de baixa energia, esses solos apresentam, normalmente, predominância das frações mais finas (argila e silte), elevadas quantidades de matéria orgânica e de sais solúveis em decorrência do contato com o mar. Por causa da decomposição da serapilheira e da saturação pela água, tais solos são de cores acinzentadas a pretas, com presença de $\mathrm{H}_{2} \mathrm{~S}$, fracamente consolidados e podendo atingir vários metros de profundidade (Cintrón \& Schaeffer-Novelli,1983).

A combinação dos el evados conteúdos de matériaorgânica com a condição anaeróbia, as fontes de $\mathrm{Fe}$ reativo (óxidos dos sedimentos) e as fontes de $\mathrm{SO}_{4}{ }^{2-}$ (água do mar) prontamente disponíveis fazem dos solos de mangue um ambiente propício à ocorrência da redução bacteriana do sulfato a sulfeto e seu conseqüente acúmulo sob a forma de pirita, desencadeando o processo conhecido como piritização ou sulfidização (Garassini, 1962; Odum, 1972; Doner \& Lynn, 1989; Rabenhorst \& Fanning, 1989; Breemen \& Buurman, 1998; Demas \& Rabenhorst, 1999; Boom et al ., 1999; Cha et al., 1999; Kelly \& Webb, 1999; Böttcher et al., 2000; Otero, 2000).

Em áreas alagadas costei ras, écomum o acúmulo de materiais sulfídricos (Pirita - $\mathrm{FeS}_{2}$ ). Estes, se drenados, ou expostos a condições aeróbias, têm a passagem de seus valores de $\mathrm{pH}$ normalmente próximos à neutral idade a valores inferiores a três, por causa da oxi dação dos sulfetos e da formação de ácido sulfúrico por ela gerada (EMBRAPA, 1999).

Segundo Prakasa \& Swamy (1987), a composição mineralógica dos solos de mangue apresenta, com freqüência, seqüências relativas de minerais de argila correspondentes, principalmente, a montmorilonita > caulinita > ilita > clorita. Minerais, como o quartzo, halita ejarosita, também podem compor a assembléia mineralógica desses solos (Marius \& Lucas, 1991). Outros minerais, como a glauconita (ilita dioctaedral com $\mathrm{Fe}^{2+} \mathrm{eFe}^{3+}$ nas posições octaedrais), podem-se formar de acordo com as condições geoquímicas presentes nestes ambientes (F anning et al., 1989).

O hal omorfismo (mei o concentrado em sais e com valores de pH entre 5,0 e9,6), gerado pela influência do mar, e o hidromorfismo (meio não-percolante), causado pela marcante presença da água nos solos de mangue, tornam o intemperismo hidrolítico (perda de sílica e bases), comum em solos bem 
drenados, inoperante nestes ambientes. O intemperismo salinolítico é, portanto, priorizado, fazendo com que o processo cristaloquímico da bissialitização predomine nestes solos.

A origem dos argilominerais em ambientes costeiros com influência constante dos aportes marinhos e fluviais pode ser de dois tipos: detrital (alóctone) ou autóctone. Argilominerais de origem detrital são trazidos de outros ambientes pela ação hídrica e, ou, eólica, enquanto os argilominerais autóctones são formados in situ. A origem autóctone de argilomineras, por sua vez, pode ter dois caminhos: a precipitação direta, a partir de íons presentes na sol ução (halmi rólise), ea transformação, a partir de um mineral precursor (Hillier, 1995).

Partindo da hipótese de que os solos de mangue encontram-seemambientehalomórfico, hidromórfico, sulfato redutor, devendo, portanto, a mineralogia destes solos corresponder a estas condições, o objetivo deste trabal ho foi caracterizar e classificar três sol os de mangue do rio I riri por meio do estudo da sua mineralogia da fração argila e sua geoquímica, com vistas em identificar os possíveis processos mineralógicos atuantes nestes solos.

\section{MATERIAL E MÉTODOS}

\section{Localização}

A área de estudo está inserta no canal de Bertioga entre as longitudes $46^{\circ} 12^{\prime} 28^{\prime \prime}$ - 46 o $12^{\prime} 29^{\prime \prime} \mathrm{W}$ e latitudes 23 053 ' 49 " - 23 이 ' 43 "S, fazendo parte do município de Santos (SP), (Figura 1).

\section{Meio físico}

A região do trabal ho é marcada pela associação entre o embasamento pré-cambriano graníticognáissico do complexo Paraíba do Sul e as planícies costeiras de origem holocênica chamadas de sedimentos flúvio-marinhos quaternários.

O relevo écaracterizado por terrenos baixos mais ou menos planos, próximos ao nível do mar, com baixa densidade de drenagem, padrão meandrante, estando relacionado com planícies de restinga e com planícies de mangue. O clima atual da região, segundo a classificação de Köppen, é do tipo tropical com temperatura média do mês mais quente superior a $18{ }^{\circ} \mathrm{C}$, precipitação anual em torno de 1.600 a $2.000 \mathrm{~mm}$, ausência de estação seca eelevada umidade nos verões (Rossi, 1999). Segundo um estudo do IPT (1989), a precipitação anual em Bertioga chega a 2.767,9 mm ano-1.

A vegetação das áreas de manguezal da Baixada Santista, inclusive de Bertioga, é essencialmente homogênea, constituída de árvores dos gêneros Rhizophora, Laguncularia e Avicennia, além do arbusto Hibiscus e da erva terrestre Acrostichun (Lamberti, 1966).

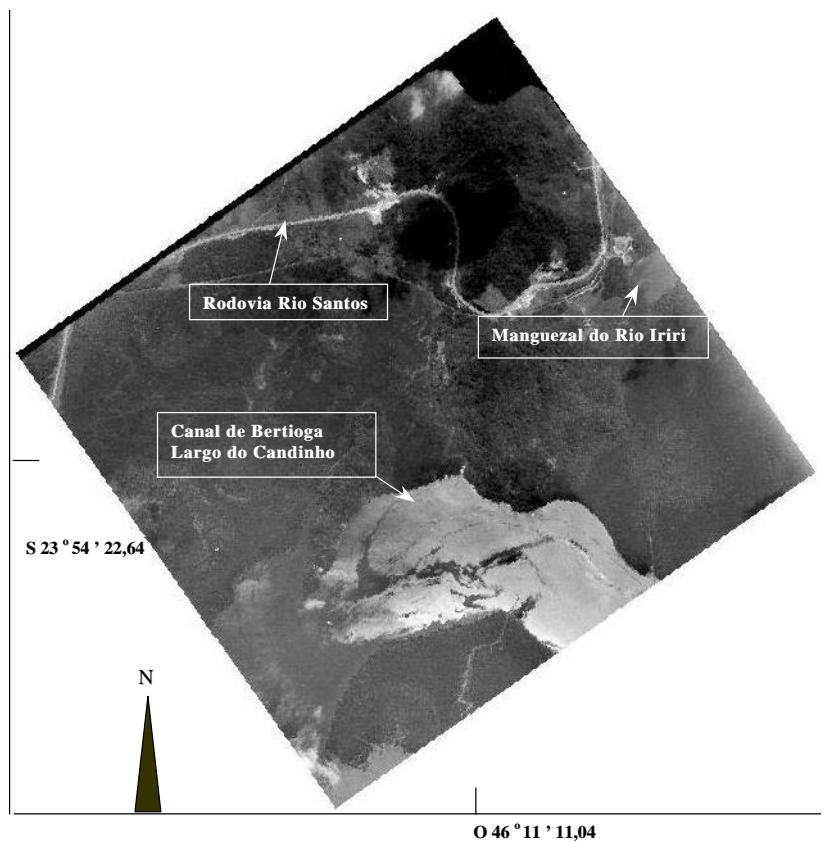

Figura 1. Localização da área de manguezal na Baixada Santista km 93 da rodovia Rio-Santos (Fotografia aérea 1:10.000, 1986).

\section{Trabalhos de campo}

Com base nas observações de campo e de fotos aéreas, uma transeção foi definida a partir do rio no sentido da encosta, considerando como zona inicial a área domanguezal no pontomais próximoà margem do rio I riri, chamada de zona da margem. A zona intermediária, localizada entre a margem ea encosta, pelas condições de encharcamento permanente, foi denominada zona alagada. Finalmente, a área mais externa e mais distante do leito do rio I riri recebeu o nome de zona de contato mangue-encosta.

As características dos solos destas zonas foram verificadas por amostragens, com amostrador cilíndrico especial para sol os inundados, realizadas a cada $10 \mathrm{~m}$ no decorrer da transeção, totalizando 30 perfis. Nestes, foram analisadas amostras de quatro profundidades (0-10, 20-30, 40-50 e 60-80 cm), determinando-se pH e Eh (no campo e, posteriormente, no laboratório), cor e textura.

Verificada a variabilidade espacial dos solos dentro da transeção, com base nas observações de campo e nos resultados das análises de campo e laboratório, foram escolhidos três perfis representativos (P3, P15 e P30) dos solos do manguezal do rio Iriri. Os perfis representativos foram então submetidos a estudos mais detal hados para fins de classificação de sol os e de caracterização mineralógica (Figura 2).

\section{Análises laboratoriais}

Para estimar a salinidade dos sol os e constatar a possível presença de caráter salino ou sálico, 
UTM W m (x10)

37704377023770037698376963769437692

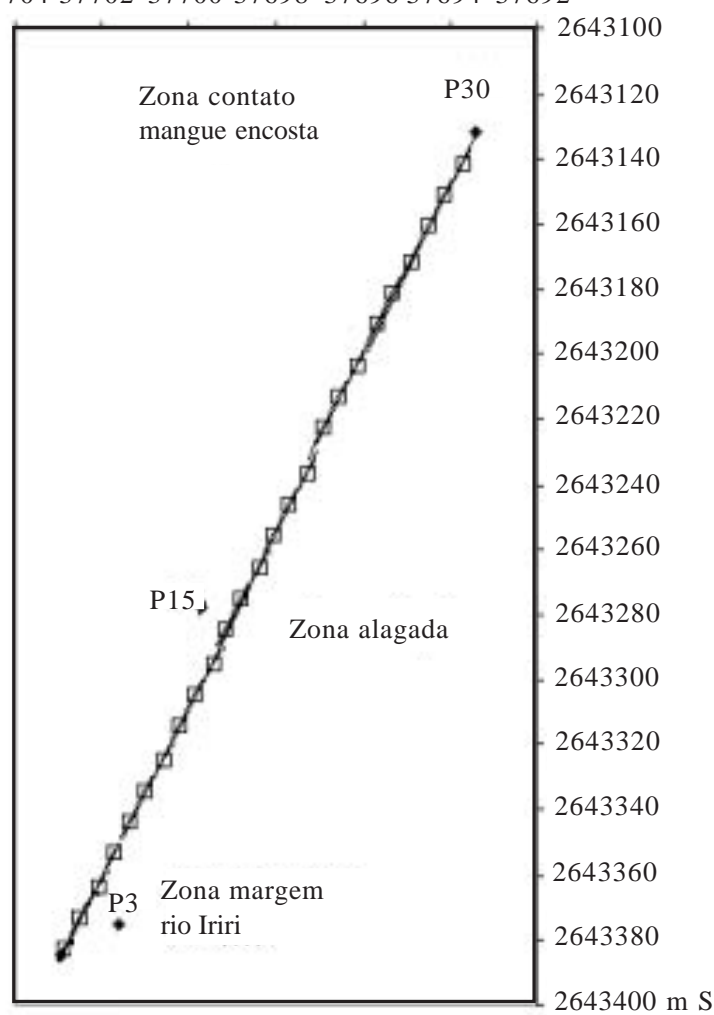

UTM

Figura 2. Croqui da transeção de $\mathbf{3 0 0} \mathrm{m}$, pontos de amostragem a cada $10 \mathrm{~m}$ e zonas descritas na área do manguezal do rio Iriri (Bertioga, SP). Destacados os perfis representativos dos solos de mangue do rio Iriri. Cada ponto de amostragem representa uma coluna de solo e quatro camadas em profundidades de 0-10, 20-30, $40-50$ e $60-80 \mathrm{~cm}$.

determinou-se a condutividade el étrica (CE) no extrato desaturação (EMBRAPA, 1997). Em virtude da elevada salinidade dos solos estudados, para a análise química dos perfis representativos, foi necessária a eliminação prévia de sais solúveis, segundo método utilizado para a análise da CTC a pH 7,0 (Camargo et al., 1986).

Efetuou-se a análise química $\left(\mathrm{pH}\right.$ em $\mathrm{H}_{2} \mathrm{O}$, matéria orgânica, fósforo assimilável, cátions trocáveis $\mathrm{Ca}, \mathrm{Mg}, \mathrm{K}, \mathrm{Na}, \mathrm{Al}$ e acidez potencial $(\mathrm{H}+\mathrm{Al})$ pel o método do acetato de cál cio), bem com a análise física de rotina, de acordo com o método descrito pela EMBRAPA (1997), além dos testes complementares para a caracterização de Organossolos (determinação da percentagem de fibra esfregada e não esfregada, determinação do grau de decomposição do material orgânico segundo a escala de von Post, ea cor do extrato de pi rofosfato), segundo o método proposto pela EMBRAPA (1999), para classificar os solos representativos da área de estudo.
Com vistas em evidenciar possível tiomorfismo, a presença de horizontes sulfúricos e, ou, materiais sulfídricos (pirita - $\mathrm{FeS}_{2}$ ) foi analisada por meio da determinação do sulfato solúvel em água, segundo o método do turbidímetro em $10 \mathrm{~mL}$ de TFSA, utilizando a sol ução extratora de acetato de amônio (Vitti, 1988).

A análise mineralógica da fração argila foi realizada em amostras orientadas e em pó, pela difração de raios-X. O preparo e o tratamento das amostras seguiram o método descrito por J ackson (1969). Após a eliminação da matéria orgânica e dos óxidos de ferro, a fração argila $(<2 \mu \mathrm{m})$ foi separada, e subamostras foram saturadas com $\mathrm{K}^{+}$ ou com $\mathrm{Mg}^{2+}$ e secas à temperatura ambiente. Difratogramas de raios-X foram obtidos no difratômetro Phillips, com tubo de Co e filtro de Fe, no intervalo 3 a $40^{\circ} 2 \theta$ de com velocidade $0,02^{\circ} \theta /$ seg. As subamostras saturadas com $\mathrm{K}^{+}$foram aquecidas a 350 e $550^{\circ} \mathrm{C}$ enquanto as saturadas com $\mathrm{Mg}^{2+}$ foram solvatadas com etileno-glicol e logo submetidas aos raios-X no intervalo de 3 a $20^{\circ} 2 \theta$.

Após a análise dos difratogramas, realizou-se a obtenção de imagens em microscópio el etrônico de varredura (MEV), juntamente com a microanálise por espectrometria de energia dispersiva de raios- $X$ (EDS), para registrar a presença e o hábito dos minerais identificados na difração de raios-X, assim como seus elementos constituintes (Souza-Santos, 1989).

\section{RESULTADOS E DISCUSSÃO}

\section{Classifi cação dos solos}

Com base nas análises químicas efísicas de rotina (Quadro 1) e nos testes complementares para caracterização de Organossolos (Quadro 2), os perfis da zona da margem, da zona alagada e da zona de contato mangue-encosta foram classificados, respectivamente, como: Organossolo Tiomórfico Hêmico térrico $(\mathrm{OJ} y)$, Organossolo Tiomórfico Fíbrico térrico (OJ y) e Gleissolo Tiomórfico Hístico sódico $(G J i)$.

De maneira geral, os três solos revelaram características morfológicas semelhantes, principalmente em profundidade, já que os dois Organossolos apresentaram material mineral inconsolidado característico de horizonte Cg, ocasionando-Ihes um enquadramento no mesmo subgrupo no $4^{\circ}$ nível categórico (térrico). A exemplo do horizonte $\mathrm{Cg}$, foi marcante nos três sol os o intenso acúmulo de matéria orgânica, conferindo-Ihes o aparecimento de horizonte hístico. No caso do Gleissolo, entretanto, oacúmulo de matéria orgânica 
Quadro 1. Análises (química e física) de rotina para fins de levantamento dos perfis representativos

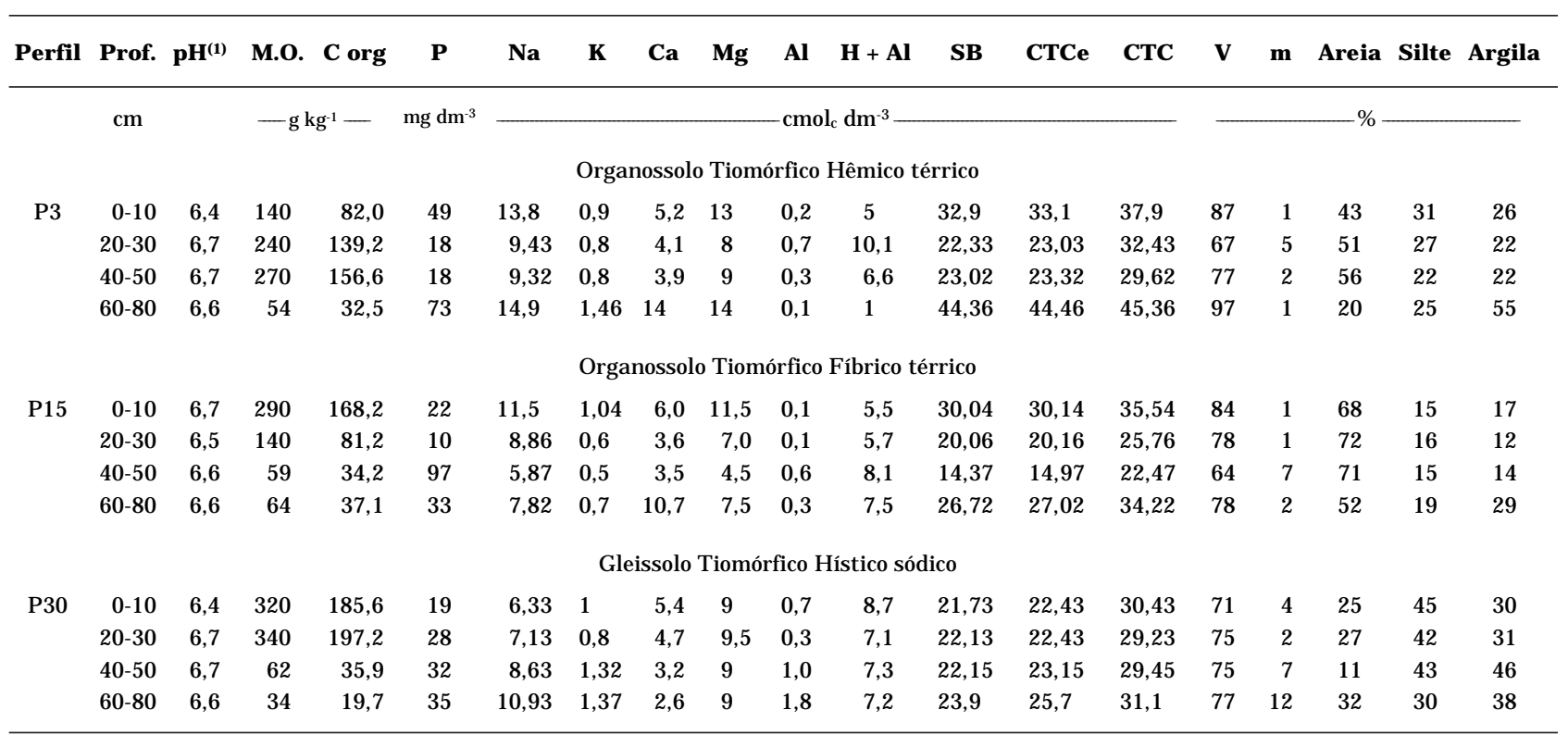

(1) Valores de $\mathrm{pH}$ medidos em campo.

não atingiu a profundidade necessária para incluíIo na classe dos Organossolos.

Os elevados teores de Na nos três solos podem ser explicados pela influência da cunha salina, ou seja, pela freqüente invasão das águas salobras na área, levando ao surgimento do caráter sódico (definido pela fórmula $100 \mathrm{Na}^{+} \pi \mathrm{T} \geq 15 \%$ segundo EMBRAPA, 1999) no $4^{\circ}$ nível categórico da classificação do Gleissolo.

Nos Organossolos, também se percebeu presença do caráter sódico, porém, em razão da ausência deste subgrupo no $4^{\circ}$ nível categórico desta classe no Sistema Brasileiro de Classificação de Sol os, os sol os foram classificados como térricos.

Os val ores de sulfato solúvel em água (Quadro 2), em todos os sol os, mostraram-se superiores ao limite de $0,05 \%$ necessário para constatar tiomorfismo (EMBRAPA, 1999) e a presença de materiais sulfídricos (Pirita - $\mathrm{FeS}_{2}$ ) nos perfis estudados. Estes dados evidenciam a ocorrência, atual ou pretérita, do processo de piritização.

A pesar das camadas ricas em S (>0,05 \% sulfatos solúveis em água), que indicariam a presença de horizontes sulfúricos sob condições de saturação, estes solos não apresentaram valores de $\mathrm{pH}$ inferiores a 3,5 devido ao efeito tampão dos sais, o que impossi bilitou a classificação de seus horizontes como sulfúricos, segundo EMBRAPA (1999).

De acordo com o Sistema Brasileiro de Classificação de Solos (EMBRAPA, 1999) nos três perfis, há domi nância de cores com val or < 4 e croma $\leq 1$ (Quadro 2), o que evidencia também o processo de gleização desencadeado pelas condições de hidromorfismo presente nos solos.

\section{Características químicas e físicas}

Do ponto de vista do complexo sortivo, os solos apresentaram também similaridades como CTC elevada graças à grande quantidade de matéria orgânica edominância dos cátions $\mathrm{MgeNa}$, seguidos por Ca e K, conferido aos sol os o caráter eutrófico.

Os valores de $\mathrm{pH}$ dos três solos representativos encontram-se entre 6,4 e 6,7, caracterizando, segundo a EMBRAPA (1999), classe de reação do tipo "praticamente neutra", sendo os baixos teores deAl eH um reflexo desta neutralidade. Além disso, os valores de $\mathrm{pH}$ e Eh se encontram na faixa característica de solos sob condições anaeróbias, conformeos val ores estipulados pela USDA (Estados Unidos, 1998) e, portanto, dentro das condições definidas como hidromórficas.

A partir dos resultados de condutividadee étrica (CE) (Quadro 2), pode-se observar um decréscimo na salinidade no sentido margem-encosta, considerando a maior influência da cunha salina no solo próximo à margem do rio. Apesar deste gradiente, todos os solos apresentam valores superiores a $7 \mathrm{dS} / \mathrm{m}$, o que, além de evidenciar o caráter sálico (EMBRAPA, 1999), caracteriza o ambiente halomórfico (meio concentrado em sais e com valores de $\mathrm{pH}$ entre 5,0 e 9,6 ) a que estão submetidos os solos do mangue do rio I riri.

A composição granul ométrica nos perfis varia de franco-arenosa no perfil da zona alagada (P15) a franco-argilosa no perfil próximo ao contato com a 
Quadro 2. Análises complementares para caracterização de Organossolos

\begin{tabular}{|c|c|c|c|c|c|c|c|c|c|c|c|c|}
\hline \multirow{2}{*}{ Perfil } & \multirow{2}{*}{ Prof. } & \multicolumn{2}{|c|}{ Proporção de fibra } & \multirow{2}{*}{$\begin{array}{c}\text { Escala } \\
\text { decomposição }\end{array}$} & \multirow{2}{*}{ CE } & \multirow{2}{*}{\multicolumn{2}{|c|}{ Teste $\mathrm{Fe}^{2+}$}} & \multicolumn{2}{|c|}{ Cor } & \multirow{2}{*}{$\begin{array}{c}\text { Classe } \\
\text { textu- } \\
\text { ral(1) }\end{array}$} & \multirow{2}{*}{$\begin{array}{l}\mathrm{SO}_{4}{ }^{2-} \\
\text { solúvel }\end{array}$} & \multirow{2}{*}{$\underset{\mathrm{CaCl}_{2}}{\mathrm{pH}}$} \\
\hline & & não esfreg & fregada & & & & & Úmido & Pirofosfato & & & \\
\hline & $\mathrm{cm}$ & 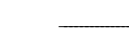 & - & & dS $m^{-1}$ & A & B & & & & $\%$ & \\
\hline \multicolumn{13}{|c|}{ Organossol o Tiomórfico Hêmico térrico } \\
\hline P3 & $0-10$ & 32,0 & 24,0 & 5-moderadamente & 15,87 & + & - & $5 Y 3 / 1$ & 10YR 7/1 & $\mathrm{F}$ & 0,26 & 5,1 \\
\hline Margem & $20-30$ & 40,0 & 24,0 & 6-bem & 23,40 & + & - & $5 Y 3 / 1$ & 10YR 7/1 & $\mathrm{FAa}$ & 0,49 & 4,6 \\
\hline \multirow{2}{*}{ rio Iriri } & $40-50$ & 36,0 & 20,0 & - & 21,40 & + & - & $2.5 Y 3 / 1$ & 10YR $7 / 2$ & $\mathrm{FAa}$ & 0,35 & 7,0 \\
\hline & $60-80$ & 8,0 & 8,0 & - & 18,00 & - & - & GLEY $3 / \mathrm{N}$ & $10 Y R 7 / 2$ & A & 0,28 & 4,9 \\
\hline \multicolumn{13}{|c|}{ Organossolo Tiomórfico Fíbrico térrico } \\
\hline P15 & $0-10$ & 56,0 & 40,0 & 2-ligeiramente & 14,40 & - & - & $5 Y 2.5 / 1$ & 10YR $7 / 2$ & FA & 0,21 & 5,6 \\
\hline \multirow[t]{3}{*}{ Alagada } & $20-30$ & 48,0 & 40,0 & 2-ligeiramente & 15,55 & - & - & $5 Y 2.5 / 1$ & 10YR $7 / 2$ & FA & 0,28 & 4,9 \\
\hline & $40-50$ & 40,0 & 32,0 & - & 13,25 & + & + & $5 Y 2.5 / 1$ & 10YR 8/1 & FA & 0,38 & 4,2 \\
\hline & $60-80$ & 36,0 & 24,0 & - & 15,35 & + & + & $5 Y 3 / 1$ & $10 Y R 7 / 2$ & $\mathrm{FAa}$ & 0,53 & 4,6 \\
\hline \multicolumn{13}{|c|}{ Gleissolo Tiomórfico Hístico sódico } \\
\hline P30 & $0-10$ & 32,0 & 16,0 & 7-fortemente & 5,74 & + & - & $5 Y 2.5 / 1$ & 10YR 6/2 & $\mathrm{Fa}$ & 0,44 & 4,3 \\
\hline Contato & $20-30$ & 12,0 & 12,0 & 8-fortemente & 11,63 & + & - & $5 Y 3 / 1$ & 10YR $7 / 2$ & $\mathrm{Fa}$ & 0,38 & 4,5 \\
\hline Mangue & $40-50$ & 8,0 & 8,0 & - & 9,98 & + & + & GLEY $3 / 5 \mathrm{GY}$ & 10YR $7 / 2$ & As & 0,42 & 4,0 \\
\hline Encosta & $60-80$ & 8,0 & 8,0 & - & 12,43 & + & + & GLEY $2.5 / 5 \mathrm{G}$ & 10YR $8 / 2$ & $\mathrm{Fa}$ & 0,46 & 4,5 \\
\hline
\end{tabular}

(1) F =Franca; $\mathrm{FAa}=$ Franco Argilo Arenosa; $\mathrm{A}=$ Argilosa; FA = Franco Arenosa; Fa = Franco Argilosa; AS = Argilo Siltosa. Escala de decomposição do material orgânico de Von Post (EMBRAPA, 1999): (1) não descomposta (d.) (2) Ligeiramente d. (3) Muito fracamente d. (4) Fracamente d. (5) Moderadamente d. (6) bem descomposta (7) fortemente d. (8) muito fortemente d. (9) quase

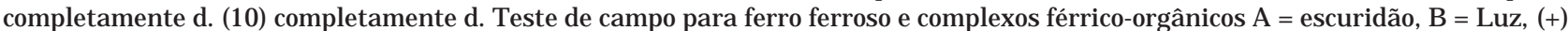
apresenta col oração vermel ha, (-) sem col oração. Solubilidade em pi rofosfato de sódio (EMBRAPA, 1999). \% sulfato solúvel em água (Vitti, 1988). pH do material orgânico em $\mathrm{CaCl}_{2}$ (20:1), (EMBRAPA, 1999).

encosta (P30), devendo-se destacar uma maior participação da fração areia no solo P 15 em relação aos outros. E ste comportamento da fração areia se deve à localização do perfil em uma área de estagnação deágua onde o fluxo hídrico perde força, causando maior deposição de areia.

\section{Difratometria de raios-X e microcopia eletrônica de varredura}

A partir de difratogramas de raios- $X$ da fração argila, foram identificadas as assembléias mineralógicas dos perfis das zonas descritas anteriormente, compostas essencialmente pelos mesmos minerais: esmectita (ES), mica (MI) e caulinita (KK) (Figura 3). Os três sol os estudados, por não apresentarem diferença na composição mineralógica, indicam a existência de condições geoquímicas similares nos três compartimentos do manguezal do rio I riri (zona al agada, zona de contato mangue-encosta e zona da margem).

Além dos picos característicos de mica, picos intensos em 0,7 e 0,35 nm marcaram a presença da caulinita nestes solos, assim como os picos de 1,45, 1,77 e $0,98 \mathrm{~nm}$ para amostras saturadas com $\mathrm{Mg}$, glicoladas e calcinadas $\left(550^{\circ} \mathrm{C}\right)$, respectivamente, indicaram a presença de um mineral do grupo das esmectitas (ES) (Figura 3).
Nas imagens de microscopia eletrônica, foram encontrados minerais com morfol ogia típica de ilita, porém, utilizando-se o EDS (microanálise pontual), picos pronunciados de $\mathrm{Fe}$ e K, característicos da estrutura da glauconita $\left(\mathrm{K}_{2}\left(\mathrm{Mg}, \mathrm{Fe}_{2}\right)_{2} \mathrm{Al}_{6}\left(\mathrm{Si}_{4} \mathrm{O}_{10}\right)_{8}(\mathrm{OH})_{12}\right)$ foram obtidos (F igura 4).

Apesar da dificuldade em discriminar uma ilita de uma glauconita em difratogramas de raios-X, não se deve descartar a possibilidade de que a mica presente nos difratogramas seja a glauconita por causa da presença de seus pi cos característicos, como descrito por Moore \& Reynolds (1989) e Srara \& Trabelsi-Ayedi (2000). Esses autores destacam as reflexões em 1,0 e 0,333 nm como os principais picos para a identificação da glauconita, os quais foram observados (Figura 3). Além disso, segundo Vanderaveroet (2000), intensas reflexões em 1,0 nm (97\%), como as observadas nas amostras aquecidas a $550{ }^{\circ} \mathrm{C}$, reforçam a existência da glauconita, assim como a fraca intensidade do pico em $0,5 \mathrm{~nm}$, causada pela presença do $\mathrm{Fe}$ nos octaedros deste argilomineral (Moore \& Reynolds, 1989).

Em outra imagem de microscopia eletrônica (Figura 5), massas granulares formadas por cristais cúbicos, típicos da estrutura da pirita, podem ser observadas. De acordo com a microanálise, evidenciou-se que esses cristais correspondem a uma 
(a)

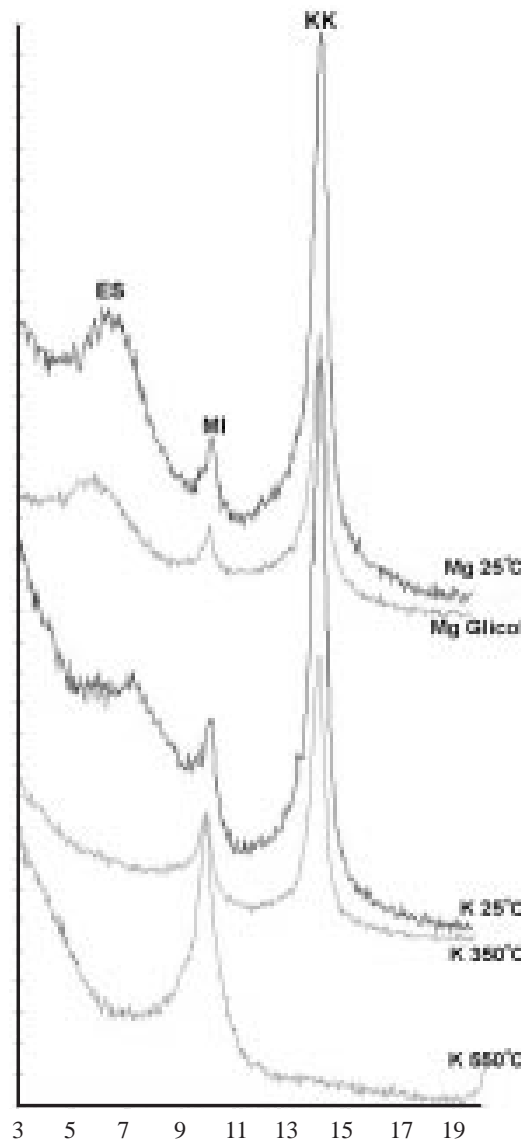

(b)

- $2 \theta \operatorname{CoK} \alpha$

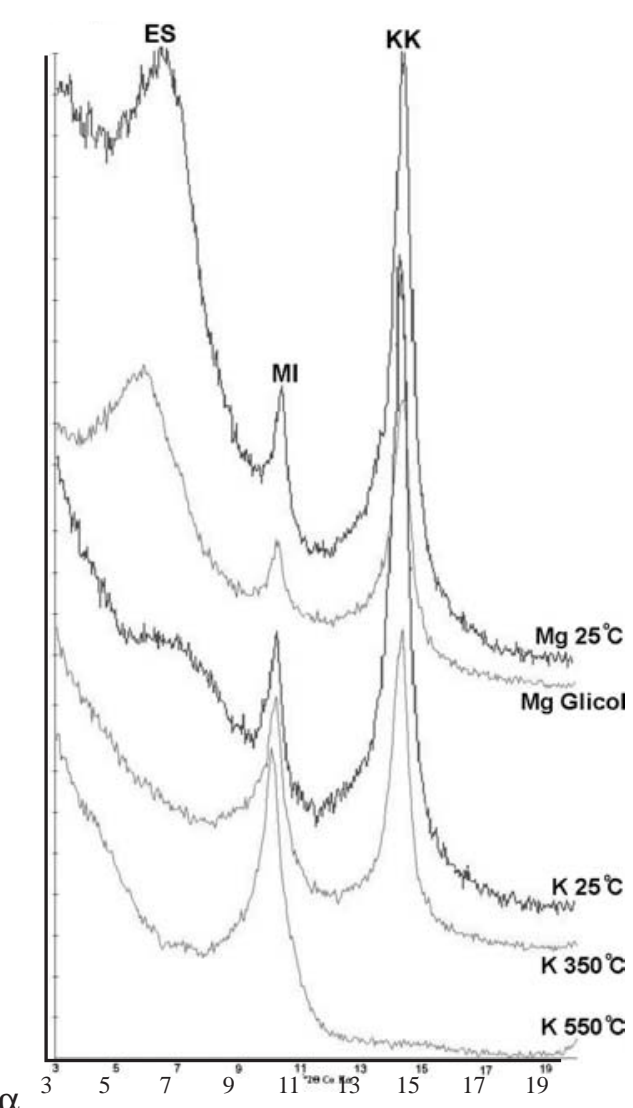

Figura 3. Difratogramas de raios-X da camada superficial (a) $(0-20 \mathrm{~cm})$ e subsuperficial (b) $(60$ a $80 \mathrm{~cm})$ dos perfis representativos (lâminas saturadas por $\mathrm{K}^{+} \mathbf{e} \mathrm{Mg}^{2+}$ ao natural, lâminas glicoladas e calcinadas).

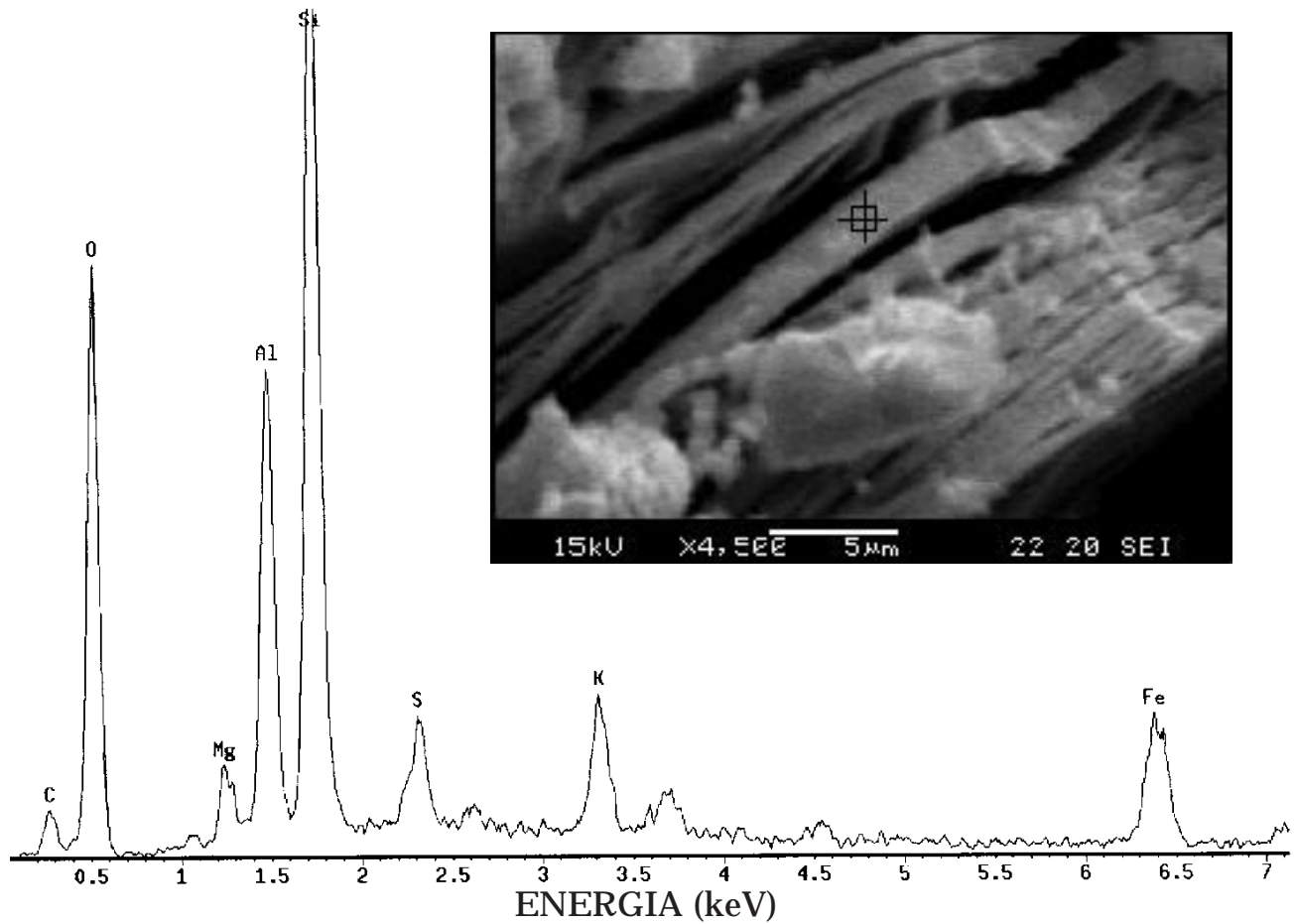

Figura 4. I magem e espectro pontual dos elementos presentes numa glauconita da camada 60 a $80 \mathrm{~cm}$ do perfil P15 (zona alagada). 
mistura de halita $(\mathrm{NaCl})$ e pirita $\left(\mathrm{FeS}_{2}\right)$, daí a existência do intenso pico de $\mathrm{Cl}$. O detalhe da figura $5 a$ mostra a presença destas formas cúbicas encobertas por partículas de outros minerais de argila e o espectro da microanálise dos elementos presentes (Figura 5b).

\section{Origem e equilíbrio geoquímico dos minerais}

No caso da pirita, a presença do sulfato, $\mathrm{Fe}$, matéria orgânica, bactérias redutoras do $\mathrm{S}$ e condições anaeróbias viabilizam o processo de sua formação no qual o sulfato é reduzido a sulfeto a partir da oxidação da matéria orgânica por meio da ação de bactérias. O Fe, por sua vez, tem sua solubilidade aumentada pelas condições redox, permitindo sua combinação com os sulfetos e dissulfetos e, conseqüentemente, a formação da pirita (Fanning \& Fanning, 1989).
Na figura 6, são apresentadas as concentrações de $\mathrm{SO}_{4}{ }^{2-}$ dos perfis representativos da transeção e as condições de $\mathrm{Eh}$ e $\mathrm{pH}$ das amostras analisadas. Pode-se constatar que as formas de Fe e S encontram-se principalmente livres na solução do solo com certa propensão à estabilidade da pirita $\left(\mathrm{FeS}_{2}\right)$.

Neste diagrama, encontram-se os perfis representativos de cada zona em relação à estabilidade de certas formas de Fe e S. Considerando que este diagrama refl ete o equilíbrio geoquímico do ambiente estuarino estudado, pode-se inferir a existência de condições favoráveis à formação da pirita, como as destacadas anteriormente, sendo elas: (a) a presença de condições redutoras evidenciadas pel os valores de Eh (b) a presença de formas reduzidas de $\mathrm{S}\left(\mathrm{S}^{\circ}, \mathrm{S}_{2} \mathrm{O}_{3}\right.$, $\mathrm{SO}_{3}$ e $\mathrm{S}_{\mathrm{x}}{ }^{2-}$ ) e (c) a presença de $\mathrm{Fe}$ na forma solúvel (ferroso).

(a)
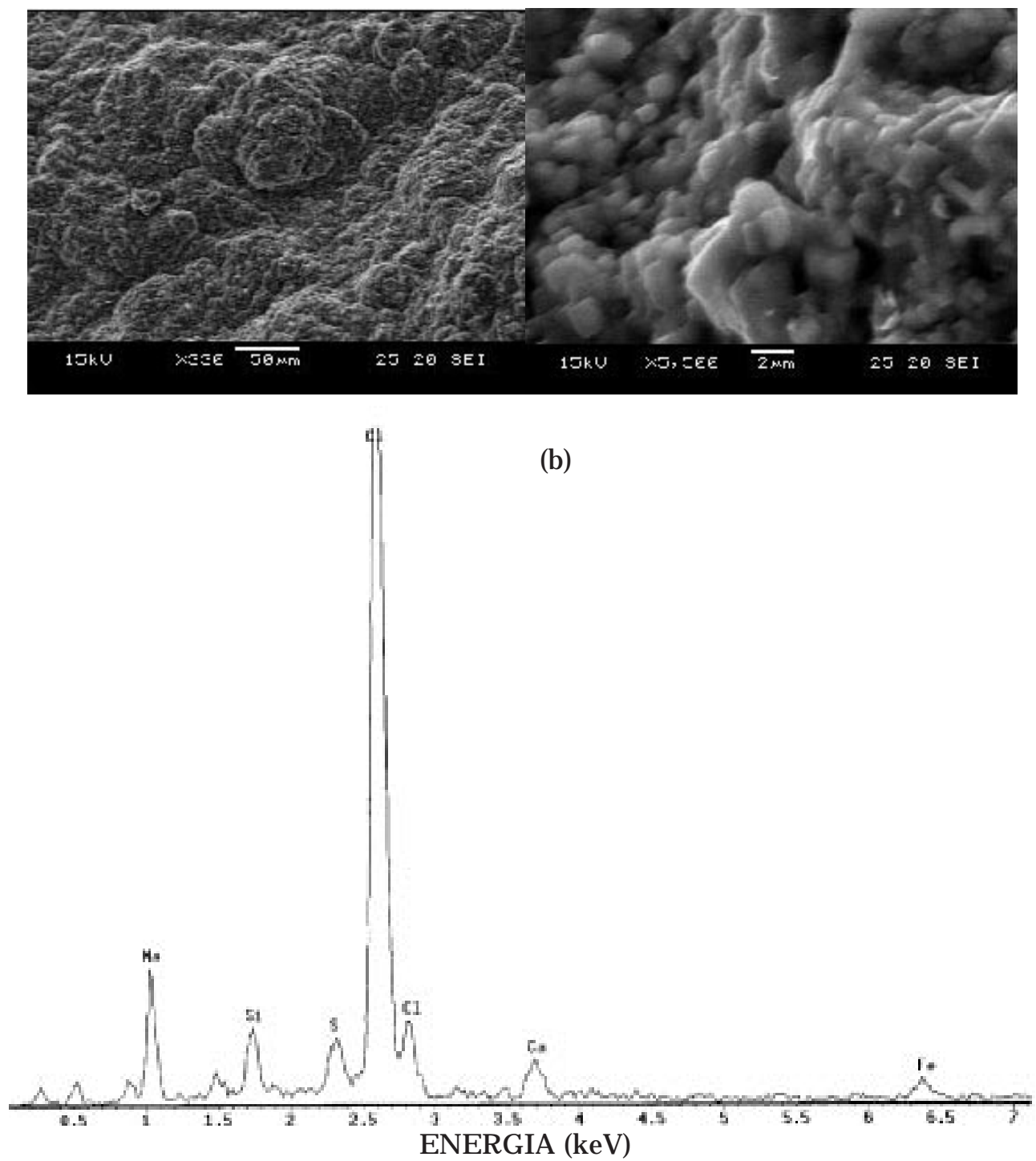

Figura 5. Morfologia cúbica, típica da estrutura da pirita, e espectro dos elementos presentes na camada de $60-80 \mathrm{~cm}$ do perfil representativo P3 (zona da margem). 


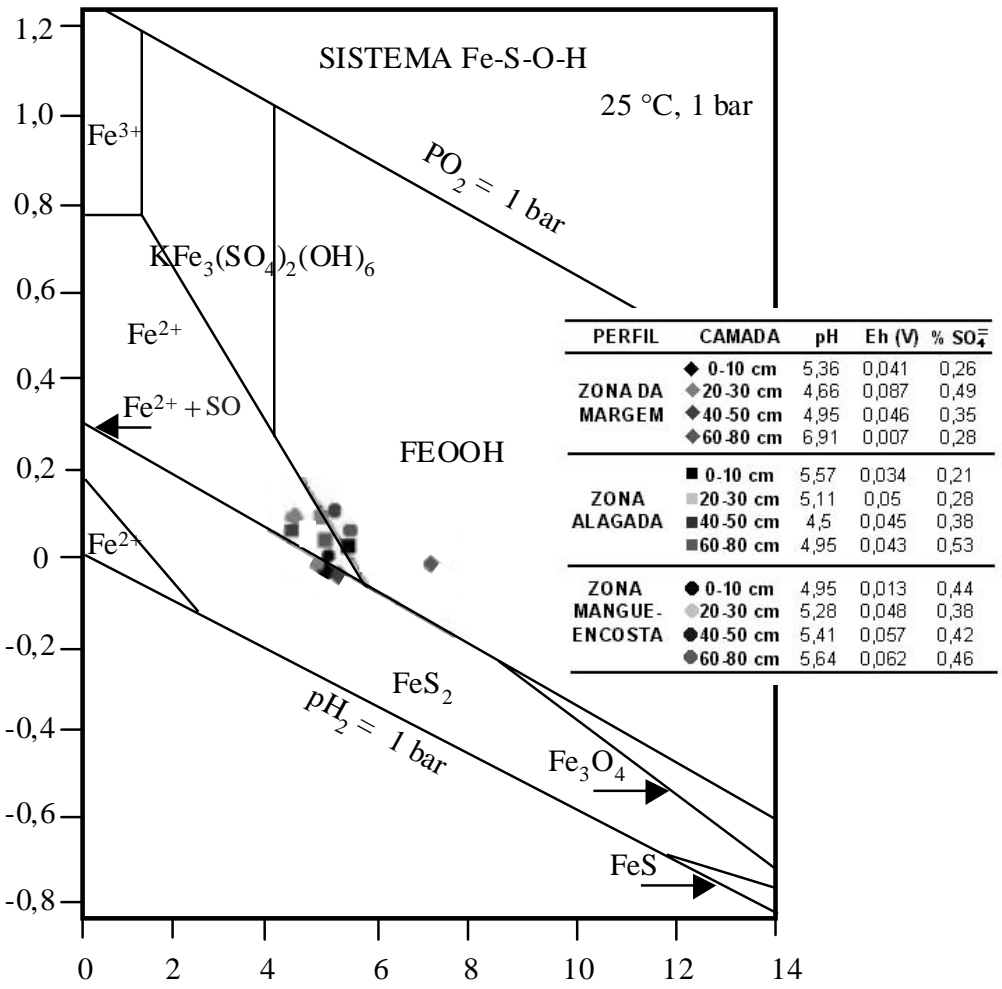

Figura 6. Diagrama E h-pH parte do sistema Fe-S-O-H, considerando a atividade $\mathrm{Fe}=10^{-6} \mathrm{eS}=10^{-3}$. Adaptado de Brookins (1988).

No caso da origem da caulinita, a intensa precipitação e sua distribuição regular ao longo do ano levariam, nos solos continentais que cercam a área de estudo, à existência de soluções de solo desprovidas de sílica ebases, favorecendo a formação deste argilomineral (Righi \& Meunier, 1995). A caulinita seria então transportada pelos sistemas fluviais e marinhos até os solos de mangue adjacentes. Este processo define uma origem alóctone da caulinita.

A neoformação (formação in situ) da caulinita se mostra dificultada sob condições desol os de mangue, já que, conforme destacado anteriormente, estes ambientes apresentam condições que favorecem a bissialitização e não a monossialitização.

Esta afirmação se encontra de acordo com o campo de estabilidade da caulinita proposto por Dixon (1989), visto que, segundo o autor, em ambientes que permitem o estabel ecimento de uma elevada relação $\left[\mathrm{K}^{+}\right] /\left[\mathrm{H}^{+}\right]$, como o presente neste estudo, o equilíbrio geoquímico é deslocado no sentido da formação de mi cas ao invés da caulinita.

As esmectitas, segundo Borchardt (1989), podemse formar a partir da transformação de micas ou então diretamente da solução do solo (neogênese). O autor destaca que, para que haja a transformação da mica em esmectita, o meio deve ter baixas concentrações de $\mathrm{K}^{+}$, o que não é observado nas condições do estudo em questão. Por outro lado, a caulinita em condições de pH acima de 6 e em meios concentrados (especial mente em $\mathrm{Si}(\mathrm{OH})_{4} \mathrm{eMg}$ ) sofre ressilicatização, transformando-se em esmectitas (montmorilonitas) (Buol et al., 1997).

Além da hipótese da transfor mação, a neogênese consistiria em uma segunda fonte geradora da esmectita, neste caso, o ambiente de alteração, caracterizado por um meio halomórfico e hidromórfico, como o encontrado neste estudo, estaria priorizando um processo salinolítico de alteração que é marcado pela remoção parcial de sílica e bases da água do rio e do mar, permitindo a bissialitização, e conseqüentemente, a formação de argilominerais do tipo 2:1.

Outra fonte de esmectita seria o aporte deste argilomineral por meio dos sistemas hídricos atuantes (rio e maré) o que definiria as esmectitas detritais (Fanning et al., 1989; Kelly \& Webb, 1999; Harris \& Whiting, 1999).

A mica presente nos solos, no caso de se tratar de uma ilita, a exemplo da caulinita, pode ser um produto do intemperismo das rochas graníticognáissicas da serra do mar, oque caracterizaria uma origem al óctone. Além da fonte detrital, a neogênese não deve ser descartada uma vez que a composição química da água do mar (valores de $\mathrm{pH}$ elevados e alta atividade de $\mathrm{K}^{+}$) favorece a formação de micas e, neste caso, segundo Fanning et al. (1989), a mica em questão seria a glauconita. 
Quanto à formação da glauconita, de modo geral, na maioria dos estudos, a autigênese aparece já na definição deste argilomineral (Suguio, 1985; Hillier, 1995; Xiouzhu et al., 1996; Sánchez-Navas et al., 1998; Suits \& Arthur, 2000); contudo, al guns autores defendem sua origem a partir de esmectitas via fixação de K + (Porrenga, 1966 citado por $F$ anning et al., 1989).

\section{CONCLUSÕES}

1. Os três solos estudados não apresentaram diferença quanto às condições geoquímicas a que estão submetidos.

2. Os solos de mangue do rio I riri encontram-se sob condições hidromórficas, hal omórficas e sulfato redutoras.

3. A morfologia, a assembléia mineralógica e as condições físico-químicas a que estão submetidos os solos evidenciam a ocorrência de processos de gl eização e piritização.

4. O ambiente geoquímico desenvolvido nas condições estudadas mantém no sol o um equilíbrio onde el ementos como o $\mathrm{Fe}^{2+}$ e o enxofre zero valente encontram-se livres, favorecendo a formação de minerais sulfídricos como a pirita.

5. A mineralogia dos três solos estudados apresenta dois tipos de origem: alóctone (caulinitas, micas e esmectitas), representada por minerais desenvolvidos na plataforma continental; autóctone (mica, esmectitas e pirita), representada por minerais desenvol vidos em ambientes concentrados (hal omórficos) e freqüentemente saturados com água (hidromórficos).

\section{AGRADECIMENTOS}

Ao Departamento de Geociências da UNESP-Rio Claro e ao NUPE GEL-ESALQ/USP, pelo auxílio na realização das análises de raios-X e análises químicas no microscópio de varredura.

À FUNDAYACUCHO - Fundación Gran Mariscal de Ayacucho, Venezuela, pelo crédito educativo concedido à primeira autora.

\section{LITE RATURA CITADA}

BOOM, M.; BRASSER, H.J .; HANSFORD, G.S. \& HEIJ NEN, J.J . Comparison of the oxidation kinetics of different pyrites in the presence of Thiobacillus ferrooxidans or Leptospirillum ferrooxidans. Hydrometallurgy, 53:57-72, 1999.
BORCHARDT, G. Smectitas. In: DIXON, J.B.\& WEED, S.B., eds. Minerals in soils environments. 2.ed. Madison, Soil Science Society of America, 1989. p.675-718.

BÖTTCHER, M.; HESPENHEIDE, B. \& LLOBET-BROSSA, E. The biogeochemistry, stable isotope geochemistry, and microbial community structure of a temperate intertidal mudflat: an integrated study. Cont. Shelf Res., 20:17491769, 2000

BREEMEN, N.V. \& BUURMAN, P. Soil formation. Dordrecht, Kluwer, 1998. 376p.

BROOKINS, D.G. Eh-pH diagrams for geochemistry. Berlin, Springer-Verlag, 1988. 176p.

BUOL, S.W.; HOLE, F.D.; MCCRACKEN, R.J . \& SOUTHARD, R.J. Soil genesis and classification. Iowa, 1997. 527p.

CAMARGO, O.A.; MONIZ, A.C.; J ORGE, J .A. \& VALADARES, J .M.A.S. Métodos de análise química, mineralógica efísica de sol os do I nstituto Agronômico de Campinas. Campinas, Instituto Agronômico de Campinas, 1986. 94p. (Boletim Técnico, 106)

CHA, J .M.; CHA, B.W.S. \& LEE, J .H. Removal of organo-sulfur odor compounds by Thiobacillus novellus SRM, sulfuroxidizing microorganisms. Process Biochem., 34:659-665, 1999.

CITRÓN, G \& SCHAEFFER-NOVELLI, Y. Introducción a la ecologia del manglar. San J uan, Rostlac, 1983. 109p.

DEMAS, G.P. \& RABENHORST, M.C. Subaqueous soils: pedogenesis in a submersed environment. Soil Sci. Soc. Am. J ., 63:1250-1257, 1999.

DIXON, J.B. Kaolin and serpentine group minerals. In: DIXON, J.B. \& WEED, S.B., eds. Minerals in soils environments. 2.ed. Madison, Soil Science Society of America, 1989. p.439525.

DONER, H.E. \& LYNN, W.C. Carbonate, halide, sulfate, and sulfide minerals. In: DIXON, J.B. \& WEED, S.B., eds. Minerals in soils environments 2.ed. Madison, Soil Science Society of America, 1989. p.279-330.

EMPRESA BRASILEIRA DE PESQUISA AGROPECUÁRIA EMBRAPA. Levantamento de reconhecimento dos solos do estado do Espírito Santo. Rio de J aneiro, Centro Nacional de Pesquisa de Solos, 1978. 379p. (Boletim Técnico, 45)

EMPRESA BRASILEIRA DE PESQUISA AGROPECUÁRIA EMBRAPA. Manual de métodos de análise de solo. 2.ed. Rio deJ aneiro, Centro Nacional de Pesquisa de Solos, 1997. 212p.

EMPRESA BRASILEIRA DE PESQUISA AGROPECUÁRIA EMBRAPA. Sistema brasileiro de classificação de solos. Rio de J aneiro, Centro Nacional de Pesquisa de Solos, 1999. $412 p$.

ESTADOS UNIDOS. National Committee for Hydric Soils. U.S. Department of Agriculture.Natural Resources Conservation Service. Hydric soil technical notes: helping people understand soils. http://www.statlab.iastate.edu/ soils/hydric. 1998.

FANNING, D.S; KERAMIDAS, V.Z. \& EL-DESOKY, M.A. Micas. In: DIXON, J .B. \& WEED, S.B., eds. Minerals in soils environments. 2.ed. Madison, Soil Science Society of America, 1989. p.551-634. 
FANNING, D.S. \& FANNING, M.C.B. Soil morfology, genesis and classification. New York, J ohn Wiley \& Sons, 1989. 395p.

GARASSINI, L.A. EI suelo y su microflora. R. Fac. Agron. Universidad Central de Venezuela, 4:1-225, 1962.

HARRIS, L.C. \& WHITING, B.M. Sequence-stratigraphic significance of Miocene to Pliocene glauconite-rich layers, on-and offshore of the US mid-atlantic margin. Sed. Geol., 34:129-147, 2000.

HILLIER, S. Erosion, sedimentation and sedimentary origin of days. In: VELDE, B., ed. Origin and mineralogy of days: days and de environment. Berlin, Springer, 1995. p.162-214.

INSTITUTO DE PESQUISAS TECNOLÓGICAS. Carta geotécnica do município do Guarujá, São Paulo, 1989. 116p.

J ACKSON, M.L. Soil chemical analysis: a advanced course. Madison, Chapman \& Hall, 1969. 894p.

KELLY, J.C. \& WEBB, J .A. Thegenesis of glaucony in the OligoMiocene Torquay group, southeastern Australia: petrographic and geochemical evidence. Sedim. Geol., 125:99-114, 1999.

LAMBERTI, A. Contribuição ao conhecimento da ecologia das plantas do manguezal de Itanhaém. São Paulo, Universidade deSãoPaulo, 1966. 217p. (Tesede Doutorado)

LANI, J .L. Deltas dos rios Doce e Itapemirim; solos, com ênfase nos Tiomórficos, água e impacto ambiental do uso. Viçosa, Universidade Federal de Viçosa, 1998. 169p. (Tese de Doutorado)

LEPSCH, I.F.; SAKAI, E. \& AMARAL, A.Z. Levantamento pedológico de reconhecimento semidetal hado da Região do Rio Ribeira do I guape no estado de São Paulo. Campinas: SAA;IAC,1983. Folha SG.23-V-A-IV-2, Escala 1:100.000.

MARIUS, C. \& LUCAS, J. Holocene mangrove swamps of West Africa: sedimentology and soils. Afric. J . Earth Sci., 12:4154, 1991.

MOORE, D.M. \& REYNOLDS, R.C. X-ray diffraction and the identification and analysis of clay minerals. New York, Oxford University Press, 1989. 332p.

ODUM, E.P. Ecología. 3.ed. México, Nueva Editorial Interamericana, 1972. 639p

OTERO, X.L Biogeoquimica de metales pesados em ambientes sedimentários marinos. Santiago de Compostela, Universidad de Santiago de Compostela, 2000. 308p.(Tese de Doutorado)
PRAKASA, R.M. \& SWAMY, A.S.R. Clay mineral distribution in the mangrove of the Godavari delta. Clay Res., 6:81-86, 1987.

RABENHORST, M.C. \& FANNING, D.S. Pyriteand tracemetals in glauconitic parent materials of Maryland. Soil Sci. Soc. Am. J ., 53:1791-1797, 1989.

RIGHI, D. \& MEUNIER, R. Origin of clays by rock weathering and soil formation. In: VELDE, B., ed. Origin and mineralogy of clays: clays and de environment. Berlin, Springer, 1995. p.43-161

ROSSI, M. Fatores formadores da paisagem litorânea: A Bacia do Guaratuba, São Paulo-Brasil. São Paulo, Universidade de São Paulo, 1999. 168p. (Tese de Doutorado)

SOUZA-SANTOS, P. Ciência e tecnologia de argilas. São Paulo, EDUSP, 1989. 1089p.

SRARA, E. \& TRABELSI-AYEDI, M. Textural properties of acid activated glauconite. Appl. Clay Sci., 17:71-84, 2000.

SANCHEZ-NAVAS, A.; MARTIN-ALGARRA. A. \& NIETO, F. Bacterially-mediated authigenesis of clays in phosphate stromal otites. Sedimentology, 43:519-533, 1998.

SCHAEFFER-NOVELLI, Y. Manguezais brasileiros. São Paulo, Universidade de São Paulo, 1991. 42p. (Tese de Livre Docência)

SUGUIO, K. Dicionário de geologia marinha. São Paulo, T. A. Queiroz, 1992. 171p.

SUGUIO, K.; MARTIN, L. \& BITTENCOURT, A.C.S.P. Flutuações do nível do mar durante o Quaternario superior ao longo do litoral brasileiro e suas implicações na sedimentação costeira. R. Bras. Geoc., 15:273-286, 1985.

SUITS, N.S. \& ARTHUR, M.A. Sulfur diagenesis and partitioning in holocene Peru shelf and upper slope sediments. Chemical Geol., 163:219-234, 2000.

VANDERAVEROET, P. Miocene to Pliostocene clay mineral sedimentation on the New J ersey shelf. Oceanol. Acta, 23:25-36, 2000.

VITTI, G.C. Avaliação e interpretação do enxofre no solo e na planta. J aboticabal, FUNEP, 1988. 37p.

XIOUZHU, Z.; YUNFEI, W. \& HUAIYAN, L. Authigenic mineralogy, depositional environments and evolution of fault-bounded lakes of the Y unnan Plateau, south-western China. Sedimentology, 43:367-380, 1996. 
R.M. PRADA-GAMERO et al.

R. Bras. Ci. Solo, 28:233-243, 2004 